\title{
Smart Sensor for Online Detection of Multiple-Combined Faults in VSD-Fed Induction Motors
}

\author{
Armando G. Garcia-Ramirez ${ }^{1}$, Roque A. Osornio-Rios ${ }^{1}$, David Granados-Lieberman ${ }^{1}$, \\ Arturo Garcia-Perez ${ }^{2}$ and Rene J. Romero-Troncoso ${ }^{2, *}$
}

1 HSPdigital-CA Mecatronica, Facultad de Ingenieria, Universidad Autonoma de Queretaro, Campus San Juan del Rio, Rio Moctezuma 249, Col. San Cayetano, San Juan del Rio, Qro. 76807, Mexico; E-Mails: aggarcia@hspdigital.org (A.G.G.-R.); raosornio@hspdigital.org (R.A.O.-R.); granlieber@hspdigital.org (D.G.-L.)

2 HSPdigital-CA Telematica, DICIS, Universidad de Guanajuato, Carr. Salamanca-Valle km 3.5+1.8, Palo Blanco, Salamanca, Gto. 36885, Mexico; E-Mail: agarcia@hspdigital.org

* Author to whom correspondence should be addressed; E-Mail: troncoso@ @spdigital.org; Tel./Fax: +52-464-647-9940.

Received: 27 July 2012; in revised form: 17 August 2012 / Accepted: 24 August 2012 /

Published: 30 August 2012

\begin{abstract}
Induction motors fed through variable speed drives (VSD) are widely used in different industrial processes. Nowadays, the industry demands the integration of smart sensors to improve the fault detection in order to reduce cost, maintenance and power consumption. Induction motors can develop one or more faults at the same time that can be produce severe damages. The combined fault identification in induction motors is a demanding task, but it has been rarely considered in spite of being a common situation, because it is difficult to identify two or more faults simultaneously. This work presents a smart sensor for online detection of simple and multiple-combined faults in induction motors fed through a VSD in a wide frequency range covering low frequencies from $3 \mathrm{~Hz}$ and high frequencies up to $60 \mathrm{~Hz}$ based on a primary sensor being a commercially available current clamp or a hall-effect sensor. The proposed smart sensor implements a methodology based on the fast Fourier transform (FFT), RMS calculation and artificial neural networks (ANN), which are processed online using digital hardware signal processing based on field programmable gate array (FPGA).
\end{abstract}

Keywords: smart sensor; induction motors; multiple-combined faults; VSD; FPGA 


\section{Introduction}

Induction motors are widely used in industry due to their robustness, low cost, easy maintenance and versatility; representing $85 \%$ of power consumption worldwide. Thus, when induction motors start developing incipient faults [1] it is important to detect the fault early because at this stage it is easier to repair, benefiting the industry in cost and maintenance time. Faults in induction motors may produce unanticipated interruptions on production lines, with severe consequences in product quality, safety and cost. For this reason, early fault detection in induction motors has attracted the interest of many researchers in recent years [2-5]. Induction motor faults are mainly associated to bearing defects (BD), rotor faults such as broken bars (BRB) [6-18], unbalance (UNB) [19] and misalignment (MAL) [20-23]. According to these faults, sometimes two or more of them may develop simultaneously, making it important to identify if they are alone or combined. Thus far, the combined fault identification in induction motors represents a big challenge, but it has been rarely considered in spite of being a common situation, because it is difficult to identify two or more faults simultaneously online through sensors [24-31]. Besides, the connection of induction motors through variable speed drives (VSD), which allow controlling their rotational speed, extending their useful life, and saving energy is a common practice in industry [32-35], but with the undesired effect of making the detection of faults more difficult because of the spurious harmonics induced by the VSD operation.

A number of vibration and current analysis-based techniques exist for identifying specific faults in induction motors. Regrettably, most of the condition-monitoring techniques for early fault detection focus on the detection of single specific faults. Broken rotor bar condition is one of the most difficult faults to detect because the induction motor works normally without perceivable anomalies, making this fault one of the most studied in research literature. For instance, in [6] the half broken bar condition is detected by combining the correlation of the vibration and current spectra. Then, a post processing technique is applied to improve the detectability and present a motor diagnosis. In a different case, in [7] the discrete wavelet transform (DWT) is applied to the instantaneous power signal to study the case of one and three broken bars for an induction motor. Otherwise, in [8] one broken bar is detected by applying the DWT to the induction motor current at the start-up transient, and through a weighting function granting the motor diagnosis. On the other hand, after unbalance, misalignment is the second most common fault causing life reduction in induction motors. For instance, in [20] misalignment is diagnosed through unique vibration features exhibited in the full spectrum computed by the fast Fourier transform (FFT). In [22] the misalignment behavior of the rotor in an induction machine is investigated with its vibration waveforms using orbit plots and conventional FFT to identify their unique vibration features. Unfortunately, few works are related to the diagnosis and the identification of multiple combined faults. Ballal et al. [25] develop a combined method with artificial neural networks (ANN) and fuzzy logic to detect stator inter-turn insulation and bearing wear faults in single-phase induction motor. They take five measurable parameters (motor intake current, speed, winding temperature, bearing temperature and the noise of the machine) for the input of the adaptive neural fuzzy inference system (ANFIS) to provide a diagnosis of the induction machine. Garcia-Perez et al. [28] proposed a method that combines a finite impulse response (FIR) filter bank with high resolution spectral analysis based on multiple signal classification (MUSIC) for detecting multiple combined faults, analyzing vibration and current signals. The results show concordance with 
the analytical predetermined fault frequency for single and two or three combined faults (BRB, UNB, and BD). Romero-Troncoso et al. [29] performed a methodology using the information entropy and a fuzzy logic analysis in an FPGA device to identify faults like BD, UNB, BRB and their combinations by analyzing one phase of the induction motor steady-state current signal. Lebaroud et al. [31] presented a diagnosis method of multiple combined faults based on time-frequency classification of the current signals. All the aforementioned theoretical frameworks focus on fault detection of induction motors directly connected to the power line supply and do not consider the case of motors connected through a variable speed drive (VSD). Therefore, few works are related to faults in induction motors connected through VSDs. For instance Obaid et al. in [32] examined the effect of changing the input frequency in an induction motor fed through a VSD with faults such as unbalance and misalignment; the work highlighted that the harmonics induced by the VSD do not change the conditions of the frequencies of interest. Other research [34], reports a methodology for the detection of broken bars in induction motors connected through a VSD at different frequencies from 30 to $60 \mathrm{~Hz}$ or directly to the power line supply and this methodology is based on electrical current transient analysis through DWT. The work of Cabal-Yepez et al. in [35] proposed the use of information entropy as a tool for multiple fault detection on induction motors controlled by a VSD obtaining results in different frequencies of operation from 30 to $50 \mathrm{~Hz}$. Unfortunately, the aforementioned methodologies are based on an offline diagnosis, except for [34] that presents an online diagnosis for BRB. From an industrial point of view an online system that ensures the diagnosis of multiple-combined faults in a VSD-fed induction motor is nowadays a necessity for reducing power consumption and preventing any further damage.

From the technological point of view, smart sensors can be used to overcome the monitoring system demands due to their versatility and ability to work in environments where the access for field workers is limited, and their features in communication and data processing functionalities [36]. On the other hand, smart sensors based on field-programmable gate arrays (FPGA) are capable of performing the task due to their high-speed processing capabilities, reconfigurability, and system-on-a-chip (SoC) solutions. Smart sensors have being applied in different research areas [36-45]. For instance, Granados-Lieberman et al. [38] developed an FPGA-based smart sensor for real-time high-resolution frequency measurement in accordance with international standards of power quality monitoring, using a current clamp as primary sensor and the chirp z-transform (CZT) as signal processing for the diagnosis. Humin et al. [39] presented a smart sensor for medium-voltage de power grid protection via current and voltage transformers. Otherwise, Rodriguez-Donate et al. [40] proposed a smart sensor to obtain several parameters related to motion dynamics using two primary sensors: an encoder and an accelerometer on a single link of industrial robots. In biology, Millan-Almaraz et al. [42] showed a smart sensor that can estimate plant transpiration. This smart sensor fuses five primary sensors: two temperature sensors, two relative humidity sensors and a light sensor. Depari et al. [44] presented a sensor network connected through a universal serial bus (USB)-to-Ethernet gateway for industrial applications. In [45] Son et al. developed a smart sensor system for machine fault diagnosis using three different sensors: vibration, current, and flux acquiring their signals, processing and diagnosing offline in a personal computer (PC). Due to their proven reliability in different research areas, smart sensors are the best suited candidates for induction motor fault monitoring systems with the presence of single or multiple-combined faults when the motor is fed through a VSD rather than having costly monitoring systems with several independent sensors and processing units connected through a computer network. 
The contribution of this work is the development of a smart sensor for on-line detection of single or multiple-combined faults in induction motors connected through a VSD over a wide frequency range, covering low frequencies from $3 \mathrm{~Hz}$ and high frequencies up to $60 \mathrm{~Hz}$, extending previously reported frequency ranges. The proposed smart sensor can use a commercially available current clamp or a Hall-effect sensor as the only primary sensor required, contrary to other works that use two or more sensors to identify a fault. The use of a current clamp as primary sensor provides additional benefits in portability, allowing one to perform the fault diagnosis in different motors without interrupting their operation. Another contribution of this work is the methodology, due to its simplicity and the theoretical foundation to analyze the frequencies of interest excited by the failure; this methodology is based on FFT fused with artificial neural networks, which is implemented into an FPGA due to its high-performance computational capabilities. In the proposed methodology, FFT provides the induction motor current spectrum normalized at steady-state, which allows covering motors with different power capabilities and a wide load range; then, specific frequency components are selected to compute their RMS to be inputs of the artificial neural network, which gives an online identification of single or combined faulty conditions. In this paper, three different faults in an induction motor: BRB, UNB, MAL and their combinations are investigated. Results confirm the potentiality of the smart sensor as an instrument for single and multiple-combined faults online detection.

\section{Theoretical Background}

\subsection{Fault Effect on Stator Current Components}

This article focuses on three different induction motor faults and their combinations: broken rotor bars (BRB), unbalance (UNB), and misalignment (MAL). The presence of BRB in induction motors produces several problems, such as power quality degradation [23]. On the other hand, UNB is the most observed fault in induction motors, and can cause catastrophic damages if not remedied. Finally, MAL is the second most commonly observed fault in rotating machines, and it is estimated to cause over $70 \%$ of the rotating machinery vibration problems [20].

\subsubsection{Broken Rotor Bar}

The detection of a broken bar fault can be done by the observation of the space harmonics $f_{b r b}$ components in the motor current as a fault indicator:

$$
f_{b r b}=f(1 \pm 2 k s)
$$

where $f$ is the input frequency, $k$ is the harmonic index, $s$ is the slip. These components are known as left sideband component and right sideband component. When a bar is broken, the amplitude of these sideband components increases significantly, as shown in Figure 1, where the markers shown delimit the sideband component area [23]. 


\subsubsection{Unbalance}

The unbalance condition is presented when the mechanical load in the induction motor is not uniformly distributed, taking the center of mass out of the motor shaft. Unbalance in induction machines creates air-gap eccentricities, which change the frequency spectrum of the supply current [19].

Figure 1. Left and right sideband components. (a) Healthy motor; (b) Broken rotor bar fault.

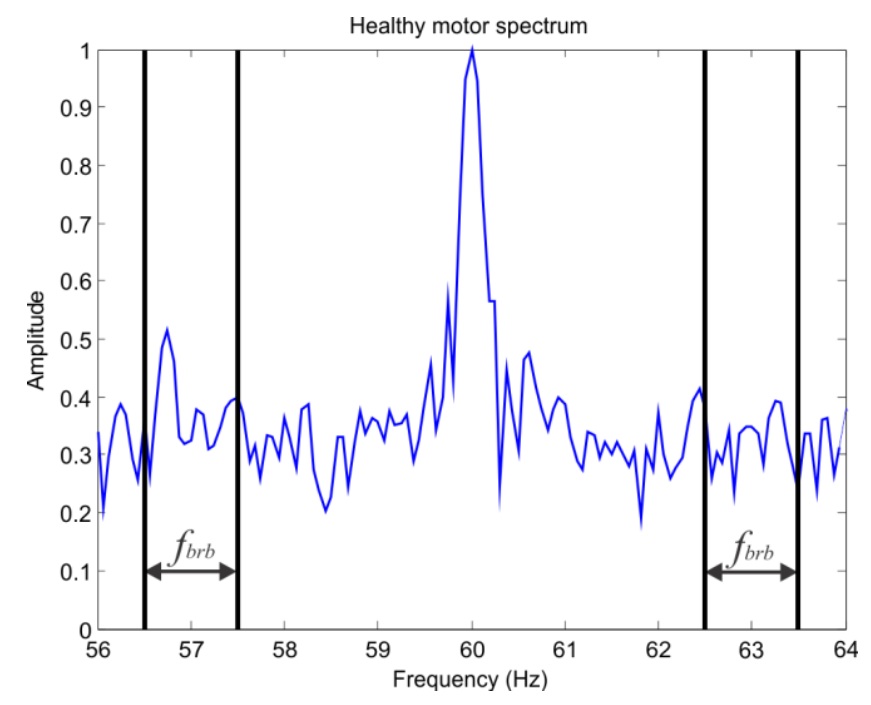

(a)

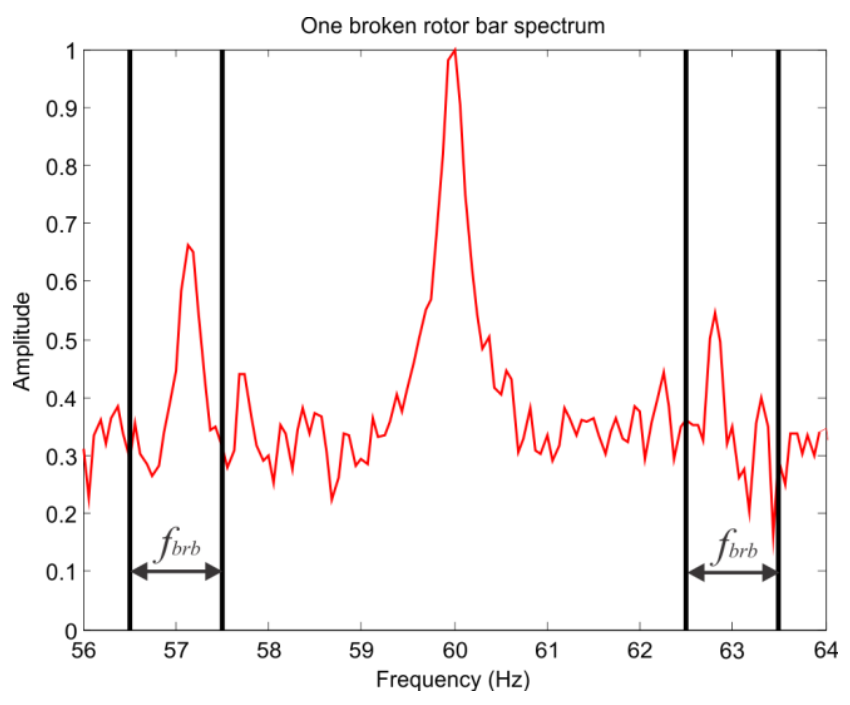

(b)

\subsubsection{Misalignment}

The misalignment in induction motors occurs when the motor and the load pulleys are not aligned. The misalignment condition, like unbalance, creates air-gap eccentricities changing the frequency spectrum of the supply current [19]. The air-gap eccentricity affects the inductances of the motor resulting in harmonics $\left(f_{e c c}\right)$ at rotating frequency sidebands of the supply frequency predicted by Equation (2):

$$
f_{e c c}=f\left[1 \pm k\left(\frac{1-s}{p}\right)\right]
$$

where $p$ is the number of pole pairs. Figure 2(a) shows the air-gap eccentricities in the healthy motor current spectrum and Figure 2(b) shows the air-gap eccentricities in a motor current spectrum with unbalance where the regions of interest are delimited.

\subsection{Artificial Neural Networks}

Artificial neural networks (ANN) are computational models that simulate the neurological structure of the human brain and its capability to learn and solve problems through pattern recognition. There are different ANN architectures, such as multilayer feed-forward networks (MFN), recurrent networks, feedback networks, radial basis function networks, and Kohonen self-organizing map networks. The most popular architecture for ANN is the MFN that has an input layer, an output layer and one or more hidden layers. In this ANN architecture the data moves in only one direction, from the input neurons 
through the hidden neurons to the output neurons, as shown in Figure 3 . Where $X_{i}(i=1,2, \ldots, n)$ are inputs and $y_{i}(i=1,2, \ldots, m)$ are outputs. An MFN is usually trained by the back-propagation algorithm (BPA), which is a supervised learning method, and consists on mapping the process inputs to the desired outputs by minimizing the error between the desired outputs and the calculated outputs [46]. The MFN architecture is simple and practical in terms of classifier and computational load, making it an excellent candidate to be implemented in the methodology.

Figure 2. Air-gap eccentricities. (a) Healthy motor current spectrum; (b) Motor current spectrum with air-gap eccentricities.

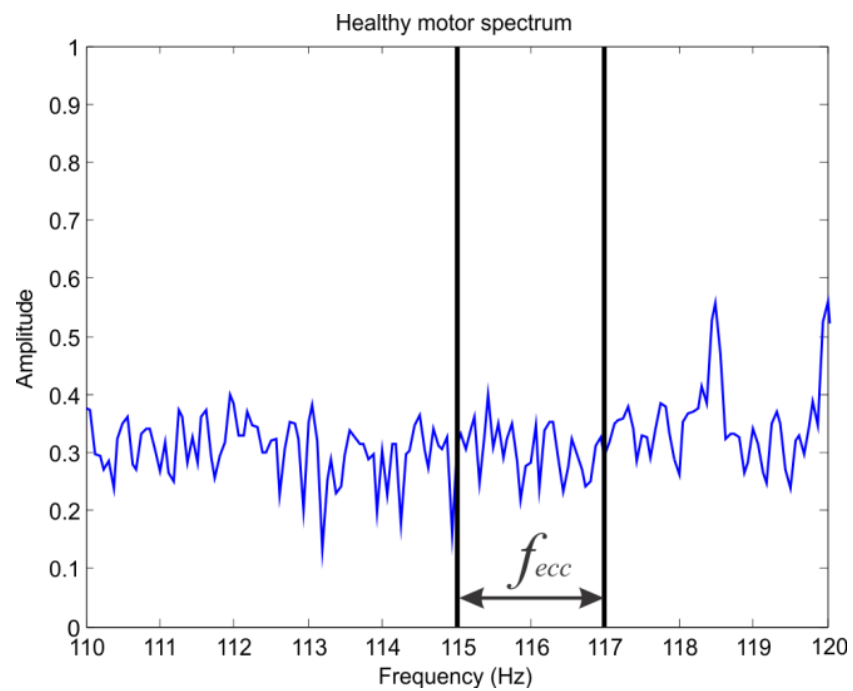

(a)

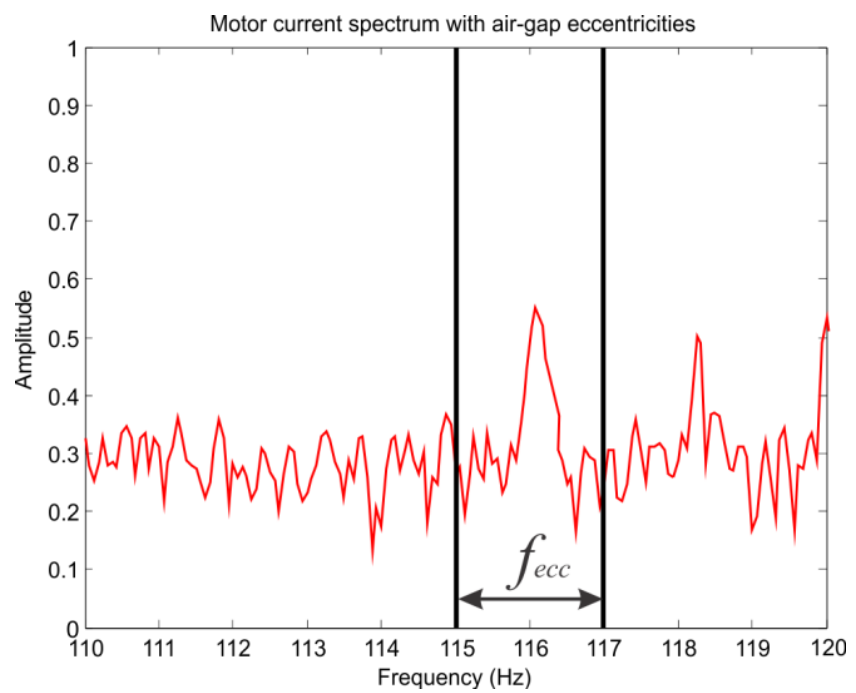

(b)

Figure 3. Multilayer feed-forward network architecture.

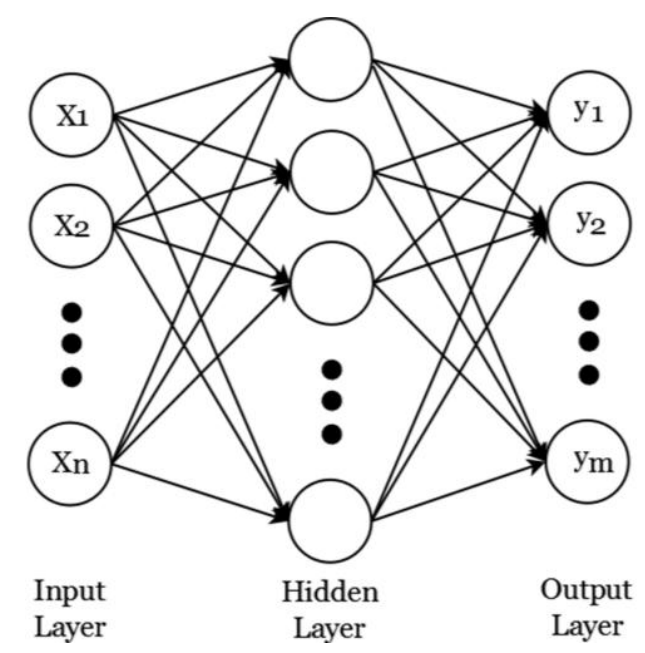

\subsection{Variable Speed Drive}

In industry the operation of induction motors through variable speed drives (VSDs) is very common, since it allows controlling their rotational speed, extending their useful life, and saving energy [32-35]. There are two different kinds of control in VSDs: Vector control drive and the Scalar control drive. The first one is an excellent driver to handle transients. It also enables fast control of 
torque speed. Some disadvantages are the complexity and the high price of the circuit. This control is commonly used in high precision tasks. As for scalar control drives, they are widely used in the industry due to their low-cost, simple design and high immunity to feedback signal errors. That type of control is preferred for simple tasks like those of pumps and fans $[47,48]$. When the speed varies under vector control drives the frequency content of the monitoring signals are affected by the controller bandwidth. However, it is possible to extract the condition monitoring information from signals derived within the controller [49]. For instance, in [50] rotor failures in induction motors, fed by a vector and scalar control, are diagnosed with three different signals: voltage, current and speed. In scalar control drives the characteristic harmonics of broken rotor bars in current are clearly visible and generate the same speed ripples, contrary to vector control drive where these harmonics are not affected and the speed spectrum is perfect.

\section{Methodology}

This section shows the proposed methodology for the smart sensor development, the configuration and the block diagram of the FPGA-based smart processor. First, the general structure of the smart sensor is discussed, then the smart processor architecture with the processing stages and finally, the proposed ANN.

\subsection{Smart Sensor}

The block diagram of Figure 4 shows the proposed smart sensor for fault detection. The system uses a primary sensor (current clamp or Hall-effect sensor) to measure one phase of the stator current in the induction motor connected through a VSD; then, signal conditioning is applied. Subsequently, the conditioned signal is digitalized in the analog-to-digital converter block (ADC). Finally, the digital information is passed through the smart processor that is in charge to assert the motor diagnostic.

Figure 4. Block diagram of the fault detector smart sensor.

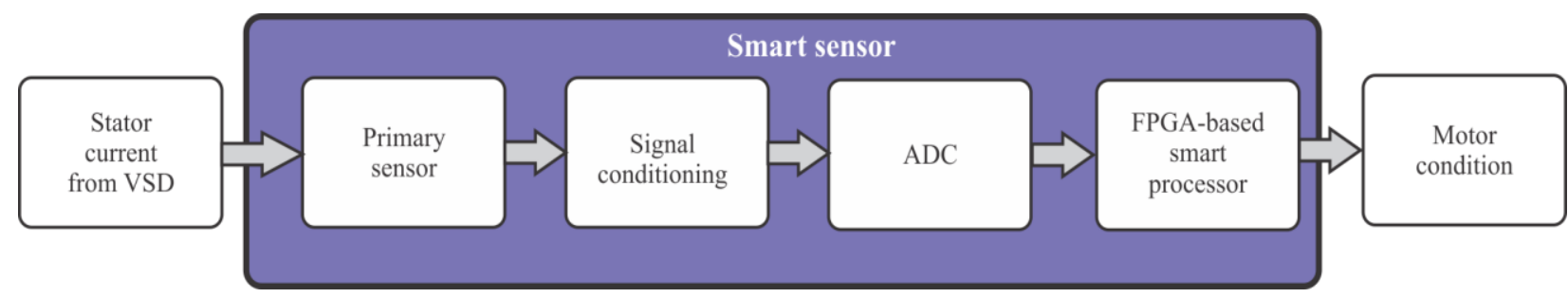

\subsubsection{FPGA-Based Smart Processor}

The block diagram of the FPGA-based smart processor internal structure to determine the condition of the motor is shown in Figure 5. The outgoing data from the ADC is time windowed with a Hanning window to reduce the leakage in the frequency domain and the frequency operation of the VSD is computed by a frequency estimator. Then, FFT is applied to get the current spectrum. In order to cover motors with different power capabilities and a wide load range the spectrum is normalized according to the magnitude of the fundamental frequency. Afterward, the bands of interest for the different faults are evaluated through the estimation of the RMS value of these selected bands 
according to Equations (3) and (4). The selection of the bands of interest is based on intervals between a minimum and maximum slip from $1 \%$ to $20 \%$ in order to fulfill the NEMA standard of A, B, C and D designs [51]. These slip percentages guarantee a motor load range between 25 to $100 \%$, nevertheless lower values of this range cannot be detected. Finally, the data from each RMS evaluator are inputs of the ANN to deliver the motor condition. Figure 6 shows the smart processing flow up to detect single and multiple-combined faults in induction motors.

Figure 5. Block diagram of the FPGA-based smart processor.

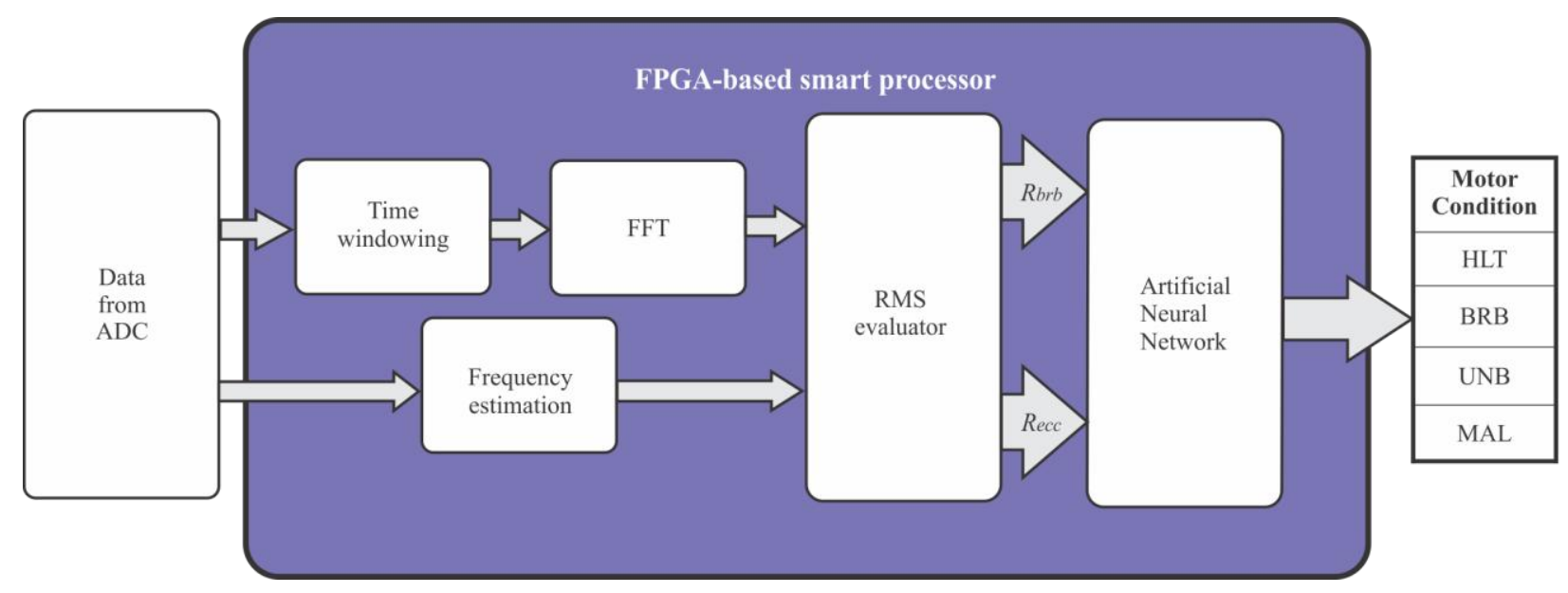

Figure 6. Smart processing flow up.
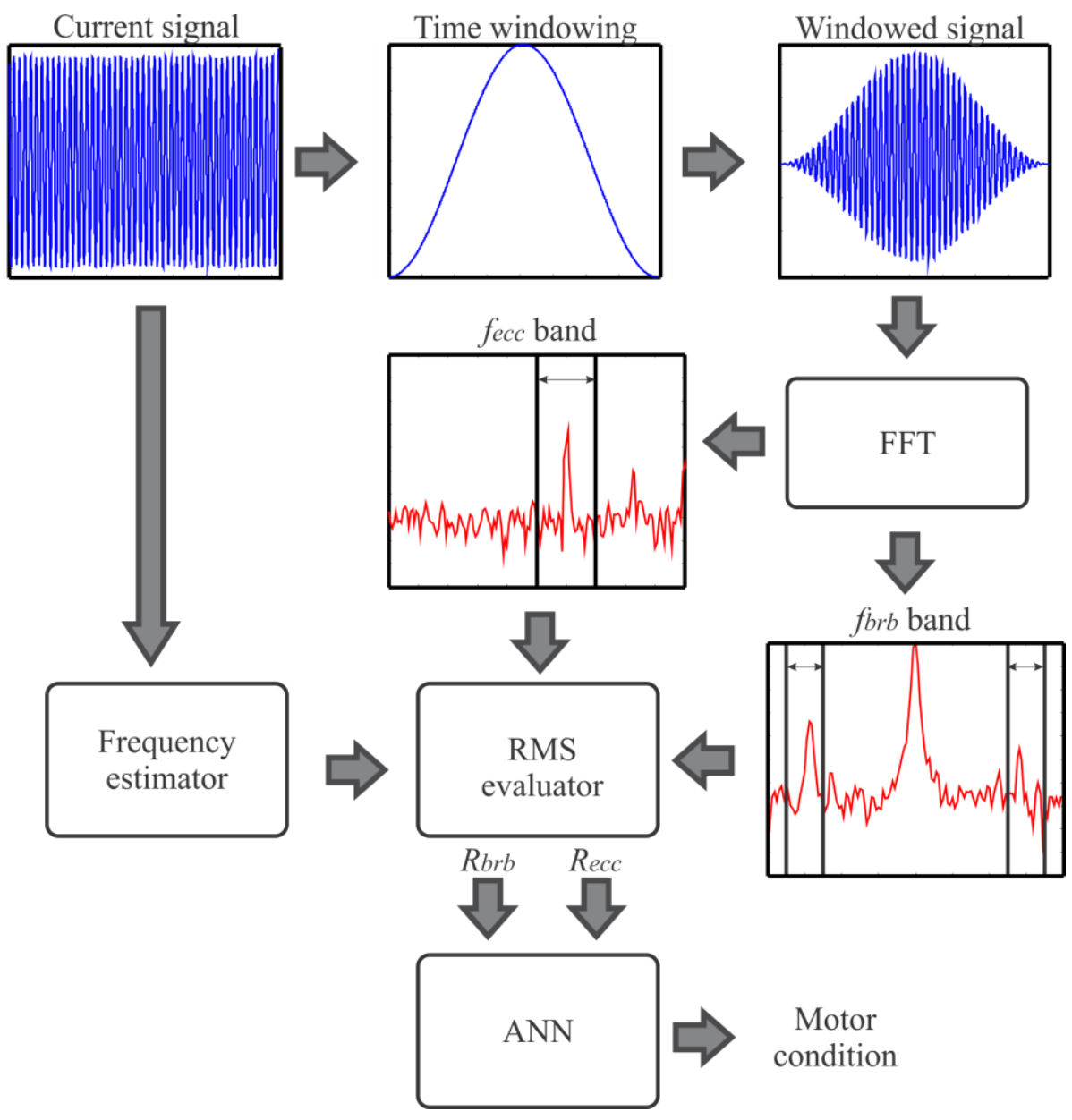


\subsection{Proposed ANN}

The proposed ANN implements an MFN with two input nodes that receive the RMS value of the left and right sideband components $\left(R_{b r b}\right)$ and the RMS value of air-gap eccentricities $\left(R_{e c c}\right)$ of the stator current from VSD, ten nodes in the hidden layer and four output nodes to detect: healthy motor (HLT), broken rotor bars (BRB), unbalance (UNB), misalignment (MAL) and their combinations. The output nodes correspond to each single fault condition, and if two or more faults are presented at the same time, the corresponding output nodes will be triggered up. Figure 7 shows the proposed ANN.

$$
\begin{gathered}
R_{e c c}=\sum_{s=0.01}^{0.20} f\left[1 \pm k\left(\frac{1-s}{p}\right)\right] \\
R_{b r b}=\sum_{s=0.01}^{0.20} f(1 \pm 2 k s)
\end{gathered}
$$

Figure 7. Proposed ANN.

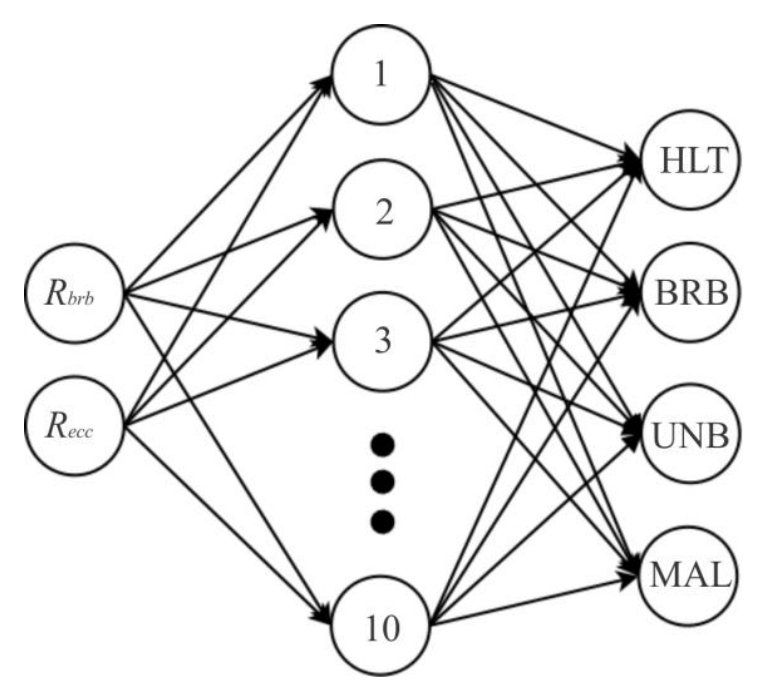

\section{Experiments and Results}

In this section, the experimental setup and the results are presented for validation the proposed smart sensor. The online fault detection was performed during the steady-state of the induction motor.

\subsection{Experimental Setup}

The experimental setup consists in using the steady-state current signal provided by a VSD (model WEG CFW08) to the motor under test for detecting the multiple-combined faults and to classify the conditions of the induction motor. The VSD has an operation range from $0 \mathrm{~Hz}$ up to $100 \mathrm{~Hz}$ using a frequency resolution of $0.01 \mathrm{~Hz}$. Figure 8(a) shows the experiment setup where three different 1-hp three-phase induction motors (model WEG 00136APE48T) are used for testing the performance of the proposed methodology identifying the single and multiple combined fault conditions treated in this work. The tested motors have 2 poles, 28 bars and receive a power supply of $220 \mathrm{~V} \mathrm{AC}$. The motor rotational speed is controlled through a VSD at $3 \mathrm{~Hz}, 30 \mathrm{~Hz}$ and $60 \mathrm{~Hz}$. The applied mechanical load is of an ordinary alternator, which represents a quarter (25\%) of nominal load for the motor. The current 
signal is acquired using a hall-effect sensor model L08P050D15, from Tamura Corporation. A 16-bit 4-channel serial-output sampling analog-to-digital converter ADS8341 from Texas Instrument Incorporated is used in the data acquisition system (DAS). The instrumentation system which was calibrated through the Fluke 435 uses a sampling frequency $f_{s}=256 \mathrm{~Hz}$ obtaining 4,096 samples during 16 seconds of the induction motor steady-state and has a bandwidth of $128 \mathrm{~Hz}$, which covers the VSD operation range. The motor start-up is controlled by a relay in order to automatize the test run. The acquired information is analyzed by the proposed smart sensor that is implemented in a proprietary Spartan 3E XC3S1600 FPGA platform running at $48 \mathrm{MHz}$ that provides the induction motor condition as shown in Figure 8(b). Table 1 summarizes the resource usage of the FPGA.

Figure 8. (a) Experiment setup; (b) Smart sensor.

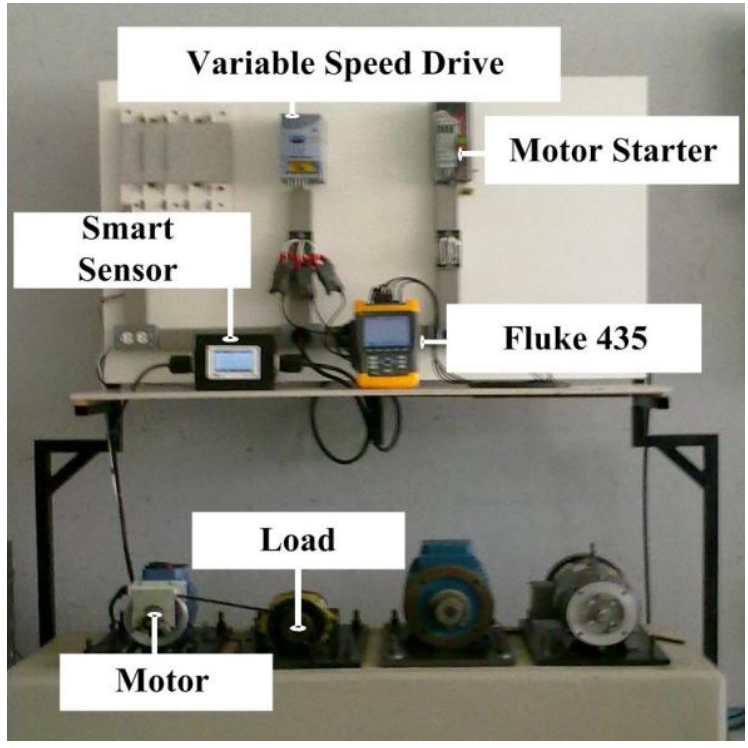

(a)

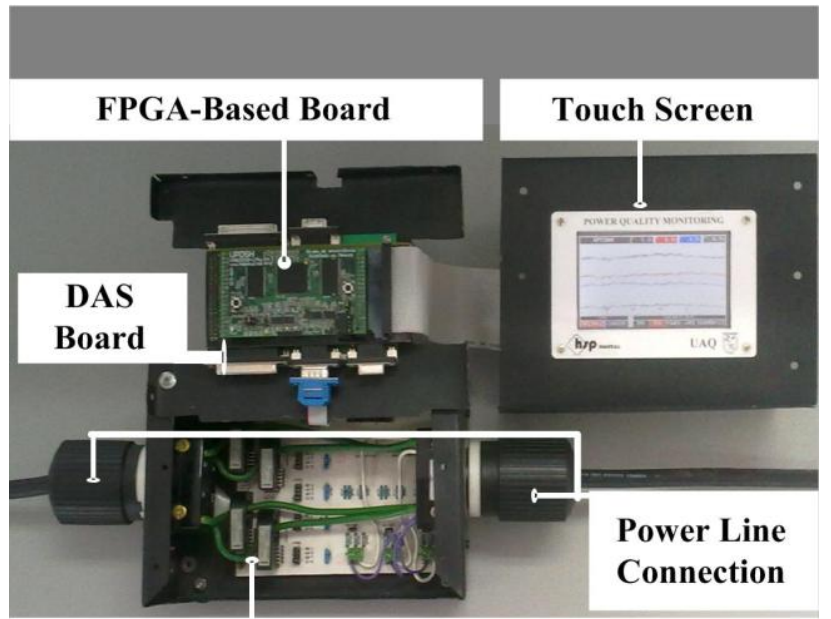

Current Signal Sampling and Conditioning Board

Table 1. Resource usage of the FPGA.

\begin{tabular}{ll}
\hline Resource utilization & Xilinx Spartan 3E XC3S1600E \\
\hline Slices & $1,757 / 14,752(12 \%)$ \\
Flip-flops & $638 / 29,504(2 \%)$ \\
4-input LUTs & $3,270 / 29,504(11 \%)$ \\
Maximum operation frequency & $53.012 \mathrm{MHz}$ \\
\hline
\end{tabular}

\subsubsection{Single Faults}

To produce an artificial broken rotor bar condition it was necessary to drill a $2.0 \mathrm{~mm}$ diameter hole in a bar of the rotor without harming the rotor shaft. Figure 9(a) shows the rotor with the broken bar used during the test. The unbalance condition was produced artificially by a bolt in the rotor pulley as shown in Figure 9(b). The misalignment test was carried out by shifting forward the band in the alternator pulley, so that the transverse axes of rotation for the motor and its load were not aligned. Figure 10(a) shows the aligned motor and the Figure 10(b) shows the misaligned motor. 
Figure 9. (a) Broken rotor bar; (b) Unbalance.

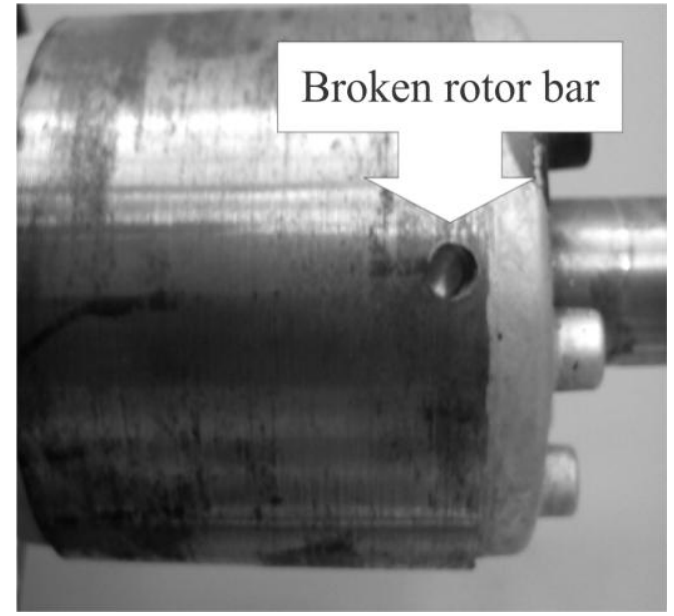

(a)

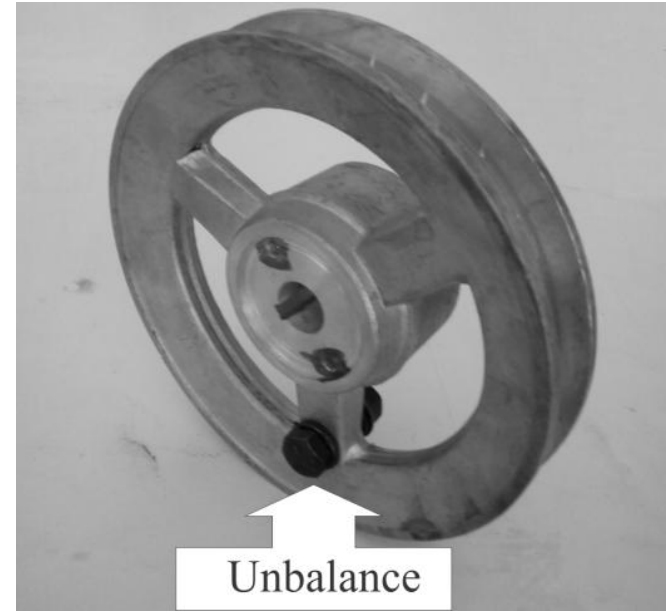

(b)

Figure 10. (a) Motor aligned; (b) Motor misaligned.

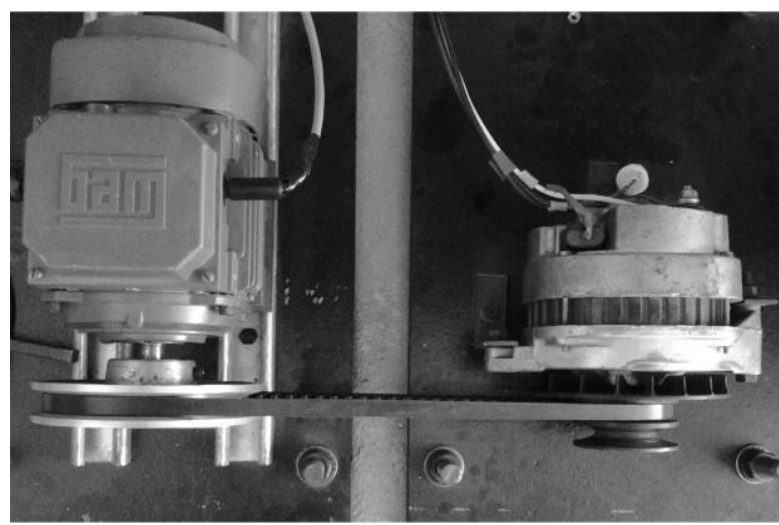

(a)

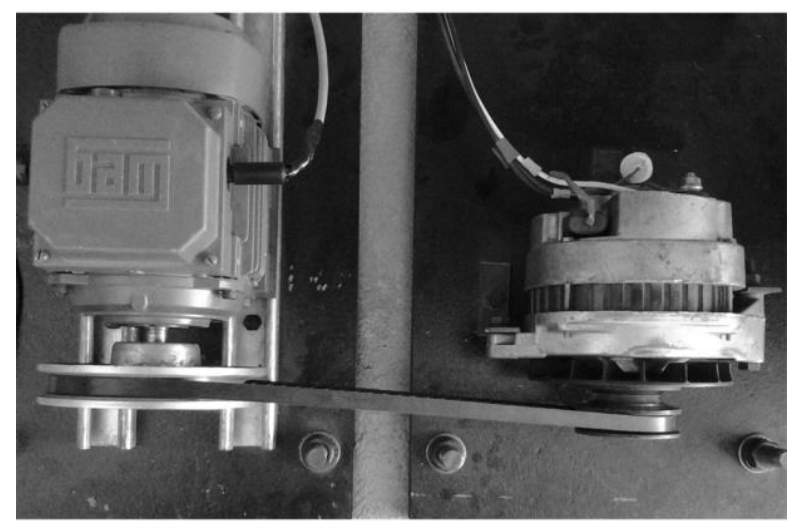

(b)

\subsubsection{Multiple-Combined Faults}

The multiple-combined fault conditions were obtained by mixing each single fault with one or two of the remaining faults as shown in Figure 11.

Figure 11. Combination for multiple-combined fault analysis.

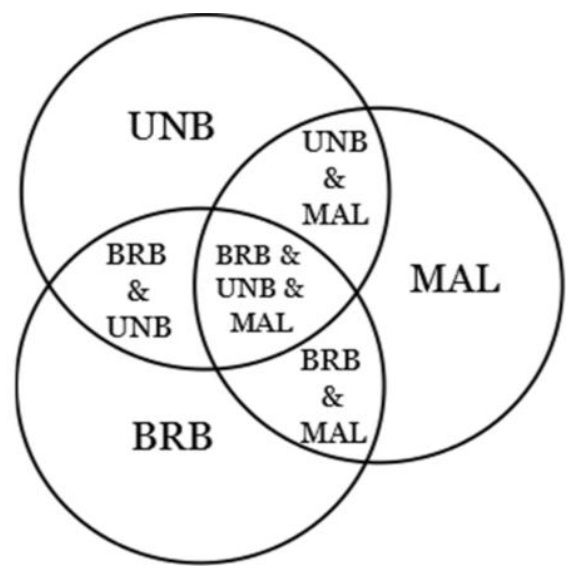




\subsubsection{Network Training}

The ANN is trained with the back-propagation algorithm to identify single or multiple-combined faults in induction motors. Forty trials are carried out under each motor condition for each study frequency. The training set was obtained with 1,000 random synthetic values for each study frequency within the range $[\mu-\sigma, \mu+\sigma]$, where $\mu$ is the mean and $\sigma$ the standard deviation of the RMS values of spectral components of interest from steady-state of the induction motor on the first five trials. Real values of each fault were used as validation set for the diagnosis. The weights and the biases of each layer in the ANN were obtained offline, using the Matlab neural network toolbox for being implemented on the FPGA for the online diagnosis. The ANN is trained for motors with B NEMA design, since those are used in general applications [51]. The theoretical background shows that the frequency components of the faults do not depend of the power motor capability. Nevertheless, the current magnitude depends of the load and the motor power. So as to minimize those undesired effects that could modify the ANN output the spectrum is normalized before being applied to the ANN. This guarantees the same results in motors with similar characteristics. However, other NEMA designs have different relationship between the fundamental frequency and the fault components because of changes in the current flux density and the stator field [5]. In some of these cases a new training is required for adjusting the calibration of the smart sensor and improving the classification results.

\subsection{Fault Identification Results}

Table 2 presents the results delivered by the proposed smart sensor during the induction motor condition identification for each frequency studied in order to show the effectiveness of the system. The results include the identification of a healthy condition, a single isolated fault, and the combination of two or three faulty conditions for each study frequency. In order to obtain statistically significant results, 40 tests were performed to acquire the current signals from the induction motor in all treated cases for each study frequency.

Table 2. Effectiveness of the proposed smart sensor on identifying the induction motor condition with one or multiple combined faults.

\begin{tabular}{lccc}
\hline Induction motor condition & 03 Hz Effectiveness (\%) & 30 Hz Effectiveness (\%) & 60 Hz Effectiveness (\%) \\
\hline HLT & 100 & 100 & 80 \\
BRB & 80 & 100 & 100 \\
UNB & 100 & 100 & 100 \\
MAL & 100 & 100 & 100 \\
BRB-UNB & 80 & 100 & 100 \\
BRB-MAL & 90 & 100 & 100 \\
UNB-MAL & 100 & 100 & 100 \\
BRB-UNB-MAL & 100 & 80 & 90 \\
\hline
\end{tabular}

\subsection{Discussion}

Three different frequency cases are studied in order to fulfill a range from low to high frequencies: $3 \mathrm{~Hz}, 30 \mathrm{~Hz}$ and $60 \mathrm{~Hz}$. Results of the smart sensor with the motor running at $3 \mathrm{~Hz}$ show an 
effectiveness of $100 \%$ in health motor (HLT), unbalance (UNB), misalignment (MAL), the combination of unbalance and misalignment (UNB-MAL) and the combination of broken bars with unbalance and misalignment (BRB-UNB-MAL); the results for broken rotor bars (BRB), broken rotor bars in combination of unbalance (BRB-UNB) and broken rotor bars combined with misalignment (BRB-MAL) present an effectiveness over $80 \%$. Due to the fact the sideband frequencies at $3 \mathrm{~Hz}$ were closer to the fundamental frequency, the conditions with broken bars were more difficult to diagnose. On the other hand, with the motor running at $30 \mathrm{~Hz}$ the smart sensor shows an effectiveness of $100 \%$ with the exception of BRB-UNB-MAL which presented an $80 \%$ effectiveness. Finally, at $60 \mathrm{~Hz}$ of the VSD, the smart sensor presents an effectiveness of $100 \%$ with the exception of HLT and BRB-UNB-MAL with effectiveness over $80 \%$. A significant characteristic of the proposed smart sensor is the detection of single and multiple-combined faults in VSD-fed induction motors in an automatic way with only a primary sensor, different from the reviewed literature where the results are from single faults or multiple-combined faults interpreted offline by the user from current of the power supply or vibration signals of the induction motor with two or more primary sensors. Table 3 shows the faults detected by the proposed smart sensor (PSS), and the works that fulfill some of the faults detected and their combination. For instance, in [29,30] show online methodologies for the detection of multiple-combined faults of induction motors connected through the power line supply. On the other hand, in [32], reports an offline methodology for the detection of UNB and MAL at different operation frequencies. In a different case, [35] presents a methodology for the detection of different single isolated faults at different operation frequencies over $30 \mathrm{~Hz}$. The PSS offers an online detection of single and multiple-combined faults at different operation frequencies in a wide range from $3 \mathrm{~Hz}$ to $60 \mathrm{~Hz}$.

Table 3. Comparison between proposed smart sensor (PSS) and reviewed literature.

\begin{tabular}{lll}
\hline Induction motor condition & VSD-fed & Power line supply \\
\hline BRB & {$[34]$, PSS } & {$[7-19,27]$} \\
UNB & {$[32,33,35]$, PSS } & {$[20]$} \\
MAL & {$[32,35]$, PSS } & {$[21-23]$} \\
BRB-UNB & PSS & {$[28-31]$} \\
BRB-MAL & PSS & {$[24]$} \\
UNB-MAL & PSS & \\
BRB-UNB-MAL & PSS & \\
\hline
\end{tabular}

\section{Conclusions}

This work proposes a new smart sensor for online detection of multiple-combined faults in VSD-fed induction motors using only a Hall-effect current sensor as primary sensor in one-phase of the induction motor, which results in a high portability. The proposed methodology is based on the FFT and an ANN classifier in order to determine the motor condition according to the motor operation frequency controlled by the VSD, the simplicity of this methodology allows analyzing the frequencies of interest excited by the different failures. The FFT spectrum is normalized in order to cover different power motor capabilities and a wide load range. The functionality of the smart sensor was successfully tested in forty tests of each category of the faults and their combinations. Results demonstrate that the 
proposed smart sensor is highly efficient in effecting a diagnosis of the induction motor operating over a wide frequency range of the $\operatorname{VSD}(3,30$ and $60 \mathrm{~Hz})$, different from other works [7-31] that show results from motors fed by the power line supply only or [32-34] that present results from VSD-fed ones, but in a narrow frequency range without combining faults. The obtained results show the versatility of the proposed smart sensor for its use in diverse industrial applications that employ induction motors fed by a VSD. The proposed smart sensor allows the early fault detection benefiting the industry in cost and maintenance time. The proposed smart sensor for online detection of multiple-combined faults in VSD-fed induction motors is based on FPGA technology that provides high computation performance for the proposed methodology, as well as a low-cost, portable and efficient solution. This implementation shows that an FPGA platform is a suitable solution for smart processing units in developing smart sensors.

\section{Acknowledgments}

This project was partially supported by CONACyT scholarship (229736), FOFIUAQ-2012, SEP-PIFI (Integral Program of Institutional Support-Universidad de Guanajuato) 2011, and SEP-CONACyT 84723 projects.

\section{References}

1. Siyambalapitiya, D.J.; Mclaren, P.G. Reliability improvement and economic benefits of on-line monitoring systems for large induction machines. IEEE Trans. Ind. Appl. 1990, 26, 1018-1025.

2. Bellini, A.; Filipetti, F.; Tassoni, C.; Capolino, G.A. Advances in diagnostic techniques for induction machines. IEEE Trans. Ind. Electron. 2008, 55, 4109-4126.

3. Tallam, R.M.; Lee, S.B.; Stone, G.C.; Kliman, G.B.; Yoo, J.; Habetler, T.G.; Harley, R.G. A survey methods for detection of stator related faults in induction machines. IEEE Trans. Ind. Appl. 2007, 43, 920-933.

4. Nandi, S.; Toliyat, H.A.; Li, X. Condition monitoring and fault diagnosis of electrical motors-A review. IEEE Trans. Energy Convers. 2005, 20, 719-729.

5. Cusido, J.; Romeral, L.; Ortega, J.A.; Garcia, A.; Riba, J. Signal injection as a fault detection technique. Sensors 2011, 11, 3356-3380.

6. Rangel-Magdaleno, J.J.; Romero-Troncoso, R.J.; Osornio-Rios, R.A.; Cabal-Yepez, E.; Contreras-Medina, L.M. Novel methodology for online half-broken-bar detection on induction motors. IEEE Trans. Instrum. Meas. 2009, 58, 1690-1698.

7. Hedayati-Kia, S.; Henao, H.; Mpanda-Mabwe, A.; Capolino, G.A. Wavelet Based Instantaneous Power Analysis for Induction Machine Fault Diagnosis. In Proceedings of 32nd Annual Conference on IEEE Industrial Electronics (IECON 2006), Paris, France, 6-10 November 2006; pp. 1229-1334.

8. Ordaz-Moreno, A.; Romero-Troncoso, R.J.; Vite-Frias, J.A.; Rivera-Gillen, J.R.; Garcia-Perez, A. Automatic online diagnosis algorithm for broken-bar detection on induction motors based on discrete wavelet transform for FPGA implementation. IEEE Trans. Ind. Electron. 2008, 5, 2193-2202. 
9. Ayhan, B.; Chow, M.; Song, M. Multiple discriminant analysis and neural-network-based monolith and partition fault-detection schemes for broken rotor bar in induction motors. IEEE Trans. Ind. Electron. 2006, 53, 1298-1308.

10. Karami, F.; Poshtan, J.; Poshtan, M. Detection of broken rotor bars in induction motors using nonlinear Kalman filters. ISA Trans. 2010, 49, 189-195.

11. Jimenez, G.A.; Muñoz, A.O.; Duarte-Mermoud, M.A. Fault detection in induction motors using Hilbert and wavelet transforms. Electr. Eng. 2007, 89, 205-220.

12. Rabelo-Baccarani, L.M.; Braga-Tavares, J.P.; Rodrigues-Menezes, B.; Matos-Caminhas, W. Sliding mode observer for on-line broken rotor bar detection. Electr. Pow. Syst. Res. 2010, 80, 1085-1089.

13. Contreras-Medina, L.M.; Romero-Troncoso, R.J.; Cabal-Yepez, E.; Rangel-Magdaleno, J.J.; Millan-Almaraz, J.R. FPGA-based multiple-channel vibration analyzer for industrial applications in induction motor failure detection. IEEE Trans. Instrum. Meas. 2010, 59, 63-72.

14. Didier, G.; Ternisien, E.; Caspary, O.; Razik, H. A new approach to detect broken rotor bars in induction machines by current spectrum analysis. Mech. Syst. Signal Process. 2007, 21, 1127-1142.

15. Supangat, R.; Ertugrul, N.; Soong, W.L.; Gray, C.; Hansen, C.; Grieger, J. Detection of broken rotor bars in induction motor using starting-current analysis and effects of loading. IEEE Proc. Electr. Power Appl. 2006, 153, 848-855.

16. Hedayati-Kia, S.; Henao, H.; Capolino, G.A. Diagnosis of broken-bar fault in induction machines using discrete wavelet transform without slip estimation. IEEE Trans. Ind. Appl. 2009, 45, 1395-1404.

17. Bellini, A.; Yazidi, A.; Filippetti, F.; Rossi, C.; Capolino, G.A. High frequency resolution techniques for rotor fault detection of induction machines. IEEE Trans. Ind. Electron. 2008, 55, 4200-4209.

18. Yahia, K.; Cardoso, A.J.M.; Zouzou, S.E.; Gueddidi, S. Broken rotor bars diagnosis in an induction motor fed from a frequency converter: Experimental research. Int. J. Syst. Assur. Eng. Manag. 2012, 3, 40-46.

19. Kral, C.; Habetler, T.G.; Harley, R.G. Detection of mechanical imbalances of induction machines without spectral analysis of time-domain signals. IEEE Trans. Ind. Appl. 2004, 40, 1101-1106.

20. Patel, T.H.; Darpe, A.K. Experimental investigations on vibration response of misaligned rotors. Mech. Syst. Signal Process. 2009, 23, 2236-2252.

21. Salem, S.B.; Bacha, K.; Chaari, A. Support vector machine-based decision for induction motor fault diagnosis using air-gap torque frequency response. Int. J. Comput. Appl. 2012, 38, doi:10.5120/4686-6812.

22. Patel, T.H.; Darpe, A.K. Vibration response of misaligned rotors. J. Sound Vib. 2009, 325, 609-628.

23. Benbouzid, M.E.H. A review of induction motors signature analysis as a medium of fault detection. IEEE Trans. Ind. Electron. 2000, 47, 984-993.

24. Antonino-Daviu, P.; Jover-Rodriguez, M.; Riera-Guasp, M.; Pineda-Sanchez, M. Arkkio, A. Detection of combined faults in induction machines with stator parallel branches through the DWT of startup current. Mech. Syst. Signal Process. 2009, 23, 2336-2351. 
25. Ballal, M.S.; Khan, H.M.; Suryawanshi, R.L.; Sonolikar, R.L. Adaptive neural fuzzy inference system for the detection of inter-turn instulation and bearing wear faults in induction motor. IEEE Trans. Ind. Eletron. 2007, 54, 250-258.

26. Wang, Y.; He, Z.; Zi, Y. Enhancement of signal denoising and multiple fault signatures detecting in rotating machinery using dual-tree complex wavelet transform. Mech. Syst. Signal Process. 2010, 24, 119-137.

27. Messaoudi, M.; Sbita, L. Multiple faults diagnosis in induction motor using the MCSA method. Hyper Sci. Int. J. Signal Image Process. 2010, 1, 190-195.

28. Garcia-Perez, A.; Romero-Troncoso, R.J.; Cabal-Yepez, E.; Osornio-Rios, R.A. The application of high-resolution spectral analysis for identifying multiple combined faults in induction motors. IEEE Trans. Ind. Electron. 2011, 58, 2002-2010.

29. Romero-Troncoso, R.J.; Saucedo-Gallaga, R.; Cabal-Yepez, E.; Garcia-Perez, A.; Osornio-Rios, R.A.; Alvarez-Salas, R.; Miranda-Vidales, H.; Huber, N. FPGA-based online detection of multiple combined faults in induction motors through information entropy and fuzzy inference. IEEE Trans. Ind. Electron. 2011, 58, 5263-5270.

30. Cabal-Yepez, E.; Valtierra-Rodriguez, M.; Romero-Troncoso, R.J.; Garcia-Perez, A.; Osornio-Rios, R.A.; Miranda-Vidales, H.; Alvares-Salas, R. FPGA-based entropy neural processor for online detection of multiple combined faults on induction motors. Mech. Syst. Signal Process. 2012, 30, 123-130.

31. Lebaroud, A.; Clerc, G. Classification of induction machine faults by optimal time-frequency representations. IEEE Trans. Ind. Electron. 2008, 55, 4290-4298.

32. Obaid, R.R.; Habetler, T.G.; Tallam, R.M. Detecting Load Unbalance and Shaft Misalignment Using Stator Current in Inverter-Driven Induction Motors. In Proceedings of Electric Machines and Drives Conference (IEMDC 2003), Atlanta, GA, USA, 1-4 June 2003; pp. 1454-1458.

33. Blödt, M.; Bonacci, D.; Regnier, J.; Chabert, M.; Faucher, J. On-line monitoring of mechanical faults in variable-speed induction motor drives using the wigner distribution. IEEE Trans. Ind. Electron. 2008, 55, 522-533.

34. Millan-Almaraz, J.R.; Romero-Troncoso, R.J.; Osornio-Rios, R.A.; Garcia-Perez, A. Wavelet-based methodology for broken bar detection in induction motors with variable-speed drive. Electr. Power Compon. Syst. 2011, 39, 271-287.

35. Cabal-Yepez, E.; Romero-Troncoso, R.J.; Garcia-Perez, A.; Osornio-Rios, R.A.; Alvarez-Salas, R. Multiple Fault Detection through Information Entropy Analysis in ASD-Fed Induction Motors. In Proceedings of 8th IEEE International Symposium on Diagnostics for Electrical Machines, Power Electronics \& Drives (SDEMPED 2011), Bologna, Italy, 5-8 September 2011; pp. 391-396.

36. Rivera, J.; Herrera, G.; Chacon, M.; Acosta, P.; Carrillo, M. Improved progressive polynomial algorithm for self-adjustment and optimal response in intelligent sensors. Sensors 2008, 8, 7410-7427.

37. Rangel-Magdaleno, J.J.; Romero-Troncoso, R.J.; Osornio-Rios, R.A.; Cabal-Yepez, E. Novel oversampling technique for improving signal-to-quantization noise ratio on accelerometer-based smart jerk sensors in CNC applications. Sensors 2009, 9, 3767-3789.

38. Granados-Lieberman, D.; Romero-Troncoso, R.J.; Cabal-Yepez, E.; Osornio-Rios, R.A.; Franco-Gasca, L.A. A real-time smart sensor for high-resolution frequency estimation in power systems. Sensors 2009, 9, 7412-7429. 
39. Humin, L.; Weilin, L.; Min, L.; Monti, A.; Ponci, F. Design of smart MVDC power grid protection. IEEE Trans. Intrum. Meas. 2011, 60, 3035-3046.

40. Rodriguez-Donate, C.; Morales-Velazquez, L.; Osornio-Rios, R.A.; Herrera-Ruiz, G.; Romero-Troncoso, R.J. FPGA-based fused smart-sensor for dynamic and vibration parameter extraction in industrial robot links. Sensors 2010, 10, 4114-4129.

41. Moreno-Tapia, S.V.; Vera-Salas, L.A.; Osornio-Rios, R.A.; Dominguez-Gonzalez, A.; Stiharu, I.; Romero-Troncoso, R.J. A field programmable gate array-based reconfigurable smart-sensor network for wireless monitoring of new generation computer numerically controlled machines. Sensors 2010, 10, 7263-7286.

42. Millan-Almaraz, J.R.; Romero-Troncoso, R.J.; Guevara-Gonzalez, R.G.; Contreras-Medina, L.M.; Carrillo-Serrano, R.V.; Osornio-Rios, R.A.; Duarte-Galvan, C.; Rios-Alcaraz, M.A.; Torres-Pacheco, I. FPGA-based fused smart sensor for real-time plant-transpiration dynamic estimation. Sensors 2010, 10, 8316-8331.

43. Rodriguez-Donate, C.; Osornio-Rios, R.A.; Rivera-Guillen, J.R.; Romero-Troncoso, R.J. Fused smart sensor network for multi-axis forward kinematics estimation in industrial robots. Sensors 2011, 11, 4335-4357.

44. Depari, A.; Flammini, A.; Marioli, D.; Taroni, A. USB sensor network for industrial applications. IEEE Trans. Instrum. Meas. 2008, 57, 1344-1349.

45. Son, J.-D.; Niu, G.; Yang, B.-S.; Hwang, D.-H.; Kang, D.-S. Development of smart sensors system for machine fault diagnosis. Expert Syst. Appl. 2009, 9, 11981-11991.

46. Huang, Y. Advances in artificial neural networks-Methodological development and application. Algorithms 2009, 2, 973-1007.

47. Holtz, J. Sensorless of induction motor drives. Proc. IEEE 2002, 90, 1359-1394.

48. WEG-CFW-08 Frequency Inverter Manual; WEG Corporation: Jaraguá do Sul, Santa Catarina, Brazil, 2006.

49. Bellini, A.; Filippetti, F.; Franceschini, G.; Tassoni, C. Closed-loop control impact on the diagnosis of induction motors faults. IEEE Trans. Ind. Appl. 2000, 36, 1318-1329.

50. Menacer, A.; Champenois, G.; Nait-Said, M.S.; Benakcha, A.; Moreau, S.; Hassaine, S. Rotor failures diagnosis of squirrel cage induction motors with different supplying sources. J. Electr. Eng. Technol. 2009, 4, 219-228.

51. Motors and Generators; ANSI/NEMA MG 1-2003 (R2004) Standards Publication; National Electrical Manufacturers Association: Rosslyn, VA, USA, 2011.

(C) 2012 by the authors; licensee MDPI, Basel, Switzerland. This article is an open access article distributed under the terms and conditions of the Creative Commons Attribution license (http://creativecommons.org/licenses/by/3.0/). 